\title{
Simulation of Construction Process Combining Steel Truss Integral Lifting with Concrete Pouring for SRC Conversion Layer Structure
}

\author{
Nianchun DENG \\ College of civil engineering and Architecture \\ Key Laboratory of Disaster Prevention and Structural Safety \\ of Ministry of Education, Key Laboratory of Disaster \\ Prevention and Engineering Safety of Guangxi \\ Guangxi University \\ Nanning, China \\ e-mail: dengnch@163.com
}

\author{
Jianhui WEI \\ College of civil engineering and Architecture \\ Key Laboratory of Disaster Prevention and Structural Safety \\ of Ministry of Education, Key Laboratory of Disaster \\ Prevention and Engineering Safety of Guangxi \\ Guangxi University \\ Nanning, China \\ e-mail: $985153771 @ q q . c o m$
}

\author{
Yu DENG \\ College of civil and architectural engineering \\ Guangxi University of science and technology \\ Liuzhou, China \\ e-mail: 150784185@qq.com
}

\begin{abstract}
The steel reinforced concrete structure is widely used in the large space structure with its excellent mechanical properties, superior economic performance and outstanding comprehensive benefit. This type of structure is a combination of structure, section steel, steel bar, concrete and other components, due to the construction sequence is not the same, the secondary stress in the structure will not be the same, the safety of the construction process will be different. In this paper, we put forward the whole lifting of the steel skeleton, and then put the concrete into the layer by layer, forming the steel reinforced concrete structure. The method has the advantages of convenient construction, short construction period, and can save a lot of cost, and need to simulate the construction process. In this paper, the construction process of the integral lifting construction of the steel reinforced concrete structure is studied in detail, then, the analysis of the structure of the steel truss lifting and load transfer process is studied. In the process of pouring concrete, the support structure is analyzed, and finally the stress process of steel reinforced concrete structure is analyzed. The research results show that the integral lifting construction method of the steel reinforced concrete structure can ensure the safety of the structure.
\end{abstract}

Keywords-high rise building; steel reinforced concrete (SRC) structure; steel reinforced concrete; construction simulation; integral lifting

\section{INTRODUCTION}

Steel reinforced concrete composite member is a member that is configured to be rolled steel or welded steel in concrete, and is also provided with a steel bar and a small amount of longitudinal stress reinforcement [1]. Steel reinforced concrete structure can save steel and can avoids the defects of rust prevention, corrosion prevention, and poor performance of fire resistance than steel structure building
[2 4]. The strength and stiffness of the steel reinforced concrete structure are larger than that of the reinforced concrete structure, and the ductility and energy dissipation capacity of the steel reinforced concrete structure are also significantly improved, especially the solid steel reinforced concrete structure is more suitable for the earthquake zone [5]. In addition, steel sections have a certain bearing capacity and can withstand a certain load, which can bring economic benefits and can speed up the construction progress in the construction process. The research of steel reinforced concrete structure began in 50s of last century, there are many differences in the design concept of various countries, mainly include: superposition method, reinforced concrete method, semi empirical and semi theoretical method, steel structure theory method [6]. The construction period is long and the process is complex [7,8]. With the development of the construction progress, the structure of the building and its corresponding stress state of the corresponding changes. Therefore, it is needed to simulate the change of building structure in different construction stages, in order to determine the strength, stiffness, crack, stability and comfort of the structure or component.

\section{PROJECT SUMMARY}

Liu Dong New Area corporate headquarters (Fig.2.1 to 2.2) project is located in Liu Dong New Area, two kilometers west of College of Lushan, Guangxi University of science and technology, bounded by new willow Avenue. Office building is a Monomer Engineering of enterprise headquarters building project, and office building is 92.80 meters high with two story underground and twenty stories on. The first layer is 5.4 meters high and Second $\sim$ twenty layers is 4.2 meters high. Structural style: Frame - core tube structure (with truss transfer story). Conversion layer truss consists of four steel reinforced concrete truss, which are 
located in the axis B, E, G, K and between 11 to 23 axis. Core tube at both ends and steel truss core tube are connected with steel reinforced concrete column, the distance between steel truss bottom and basement bottom plate is 35.60 meters, and the span and height of steel truss are $50.60 \mathrm{~m}$ and $34.30 \mathrm{~m}$ respectively.

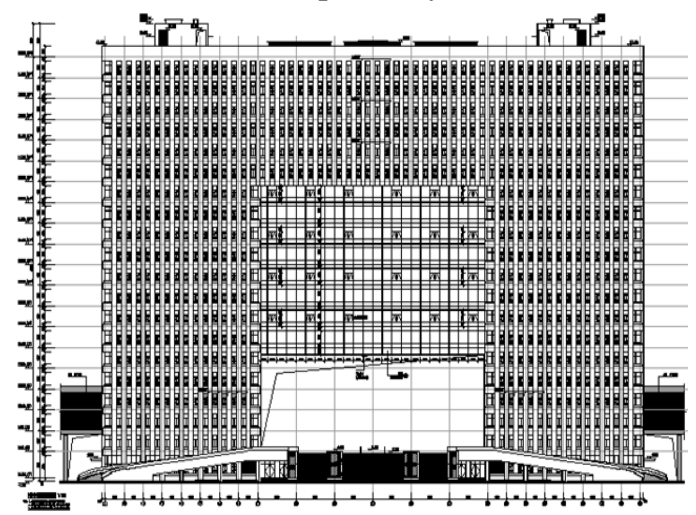

Figure 2.1. Liu Dong enterprise headquarters office building

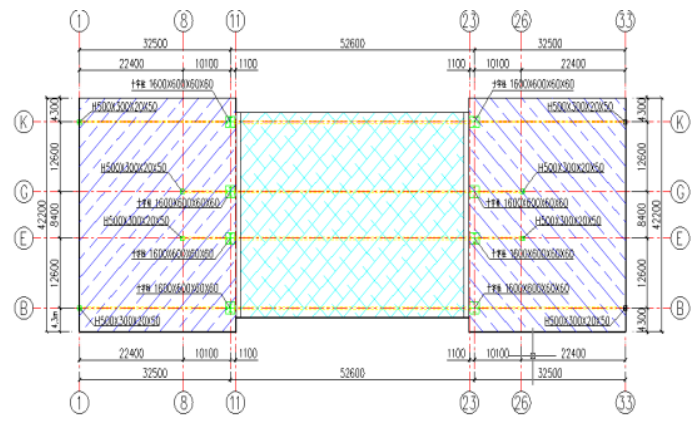

Figure 2.2. Plane layout diagram of conversion truss

\section{CONSTRUCTION PROCESS OF INTEGRAL LIFRING METHOD}

Because the concrete has the characteristics of shrinkage and creep, it is the first to complete the construction of both side towers, so that the two sides have sufficient time to complete the shrinkage and creep. The conversion layer steel truss is assembled in the basement floor and the two sides towers continue to construction layer by layer after the sixteenth storey of tower has been completed. Hoisting and closure installation of steel truss after two towers completed.

Considering the factors such as quality, duration and economic benefit and according to the successful experience of similar projects in the past, it is better to use the "super large hydraulic synchronous lifting technology" to install the steel truss. Cantilever bracket was placed on both sides of the SRC column in the 15 floor, which used to set up hydraulic lifter; top chords of the steel truss need to be reinforced and special sling was welded onto steel truss. The steel truss structure can be raised to the installation location one time by the super large hydraulic synchronous lifting technology.

The construction sequence of the headquarters building is:

Step1: Firstly, the construction of 1-16 layer tower structure is completed;
Step2: Assembly and hoisting of steel truss;

Step3: Installation of support system (lattice truss column);

Step4: Construction of conversion layer structure layer (supporting formwork, reinforcement, pouring concrete, curing);

Step5: Construction of $15 \sim 20$ layer structure.

\section{Simulation Analysis of CONSTRUCTION PROCESS}

The geometric shape, boundary condition and load along with the construction progress of the construction process, such as the dead load of the structure, the construction load and so on, are constantly changing during the construction process. According to statistics, there are more than $70 \%$ of the engineering quality problems caused by the absence of the construction process in the structural design stage in the whole country. Midas Gen finite element software have the function of the construction process analysis and can take into account the characteristics of shrinkage and creep of concrete in the construction process with the concept of cumulative model. According to the construction process the construction process is simulated by the fractional step method and the step-by-step model technology with Gen Midas finite element analysis software in this paper [9, 10].In this paper, the engineering construction stage is simulated and analyzed by the internal force and displacement extracted from the steel truss according to the corresponding calculation results.

\section{A. Stress Anslysis of Steel Lifting Process}

Two pieces of steel truss are lifted synchronously as a group during the lifting process. To enhance stability of steel truss during the lifting, the temporary support rod is fixed between two trusses. The Midas/gen software was used to simulate and calculate the lifting working conditions, and the load impact effect was considered into simulation and calculation of the lifting working condition (Fig4.1.1 4.1.2). Take two pieces of GK as an example, Steel truss and connecting rod are made of Q345 steel:

(1) The maximum stress of the temporary connecting rod: $181 \mathrm{Mpa}<310 \mathrm{Mpa} / 1.5=206 \mathrm{Mpa}$; the maximum stress of the $\mathrm{G}$ axis truss: $93.6 \mathrm{Mpa}<265 / 1.5=176 \mathrm{Mpa}$

(2) The deflection of $\mathrm{G}$ axis truss is $17.45 \mathrm{~mm}$.

The results show that the structure is safe in the process of lifting.

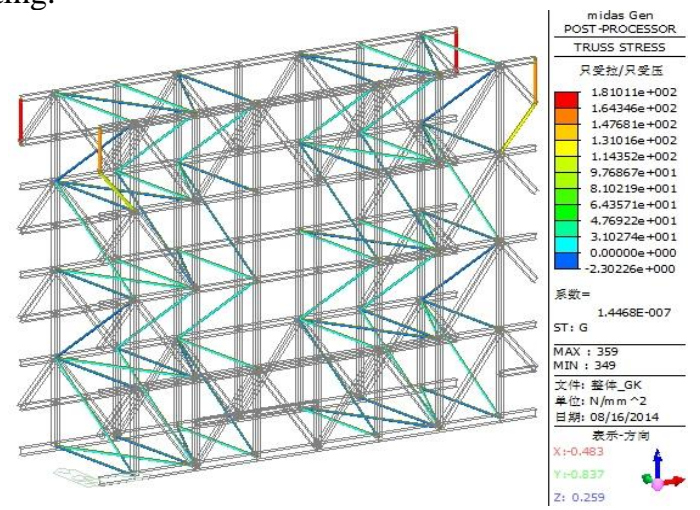

Figure 4.1.1. Provisional rod stress of GK axis 


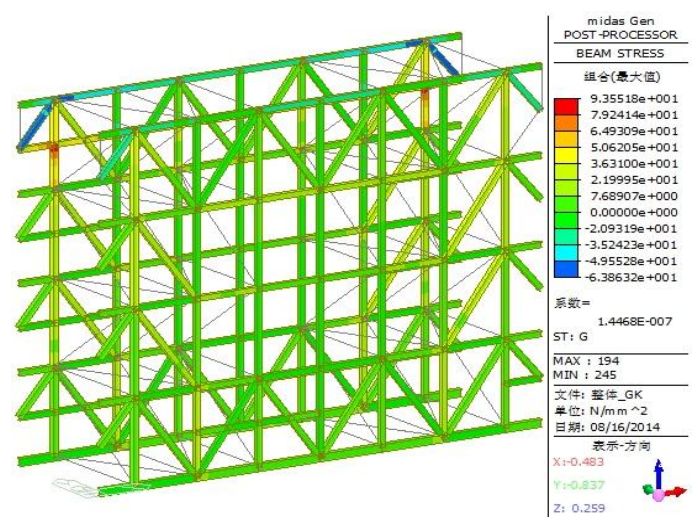

Figure 4.1.2 Truss stress of GK axis

\section{B. Force Analysis of Support Structure}

Lattice columns will be erected after closure of the steel truss installation, which are used for pouring concrete and subsequent floor construction. The construction scheme of the Lattice columns is designed according to the reaction force of the construction platform during the construction period. According to the principle of the anti- force and cost saving, the classification of the lattice column is determined. The lattice column is determined by the form of four limbs, three limbs and double limbs, and the specifications are P299X16 and P203X10. The lattice column is simulated by linear element in Midas Gen modeling, so it is necessary to simplify the lattice column. The principle of simplified treatment of lattice column model is as follows:

- Equivalent load

The load of the lattice column is equal to the load of the equivalent lattice column.

- Equivalent static force

The axial stress of the lattice column is equal to the axial stress of equivalent lattice column.

- Equivalent displacement constraint of node

Because the lattice column have lateral contact member, the plane displacement of the lattice column is controlled by the displacement of the plane of the constraint node. This reduces the part of the load.

The calculated results are as follows: 4.2.1 4.2.3.

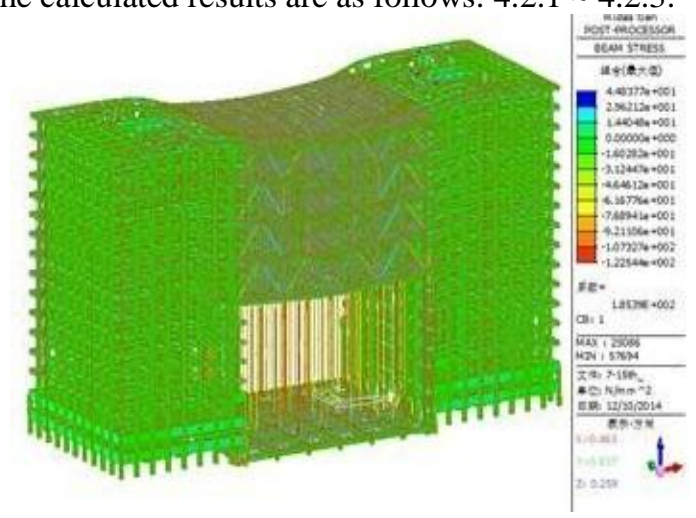

Figure 4.2.1. Lattice column stress

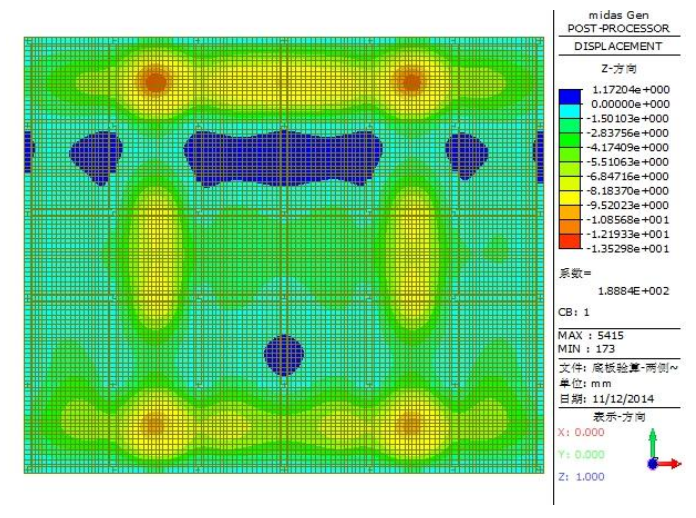

Figure 4.2.2. Displacement diagram of foundation floor

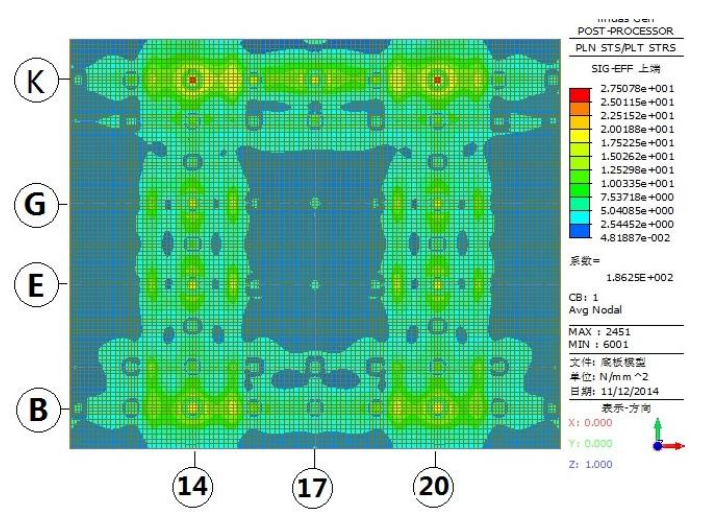

Figure 4.2.3. Foundation floor stress

The maximum stress of the lattice column is $123 \mathrm{Mpa}$, the maximum displacement of the base plate is $14 \mathrm{~mm}<28 \mathrm{~mm}$ $(1 / 300)$, the maximum stress is $27.5 \mathrm{Mpa}$, and the deformation meets the design code. The calculation results show that the base plate and the bottom plate support system satisfy with safety requirements on the structure the strength, deformation and stability.

\section{Stress Analysis of Construction Process Structure}

In this paper, based on LiuDong district headquarters office building project engineering, it is needed to simulate and analysis the working condition of each stage of the conversion layer in order to ensure the safety of the structure during the process of construction. According to the order of engineering construction, the corresponding calculation models are set up respectively, and the internal force and displacement of the truss are extracted respectively. The secondary stress of steel truss in the process of steel truss is generated by the gravity of the steel truss built and the construction load of each layer. Through analysis and calculation, the integral lifting scheme is feasible process and the structure is safe in the construction. The corresponding calculation results 4.3.1 4.3.4. 


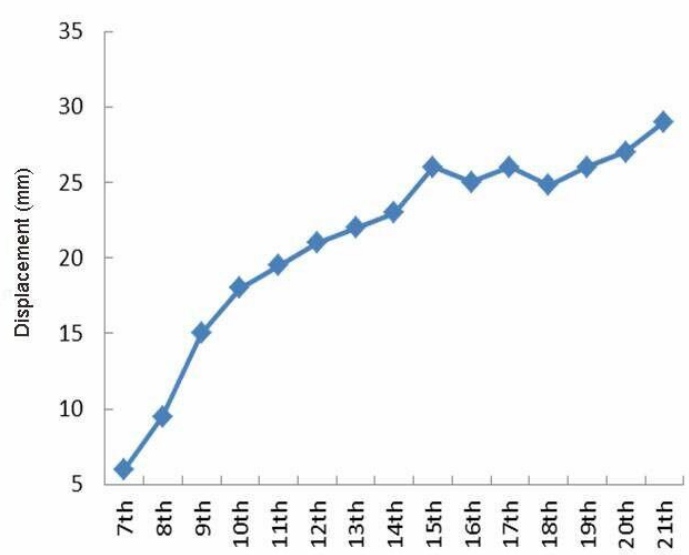

Figure 4.3.1. Displacement deformation of construction process

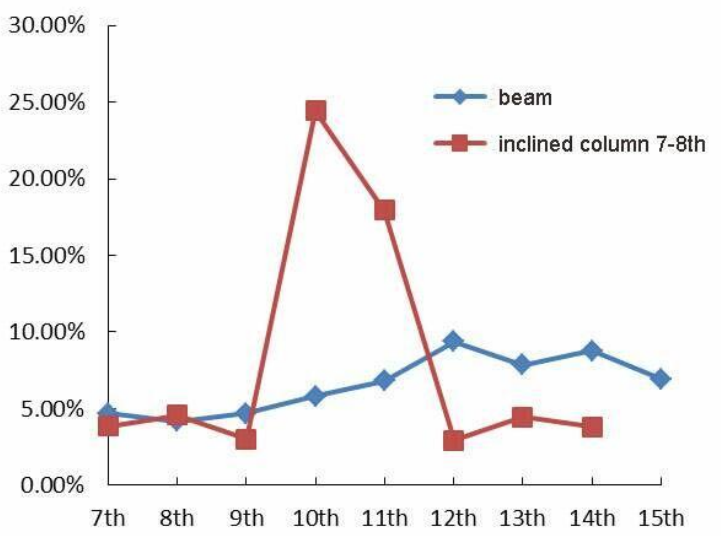

Figure 4.3.2. Influence of internal force of truss in the construction process

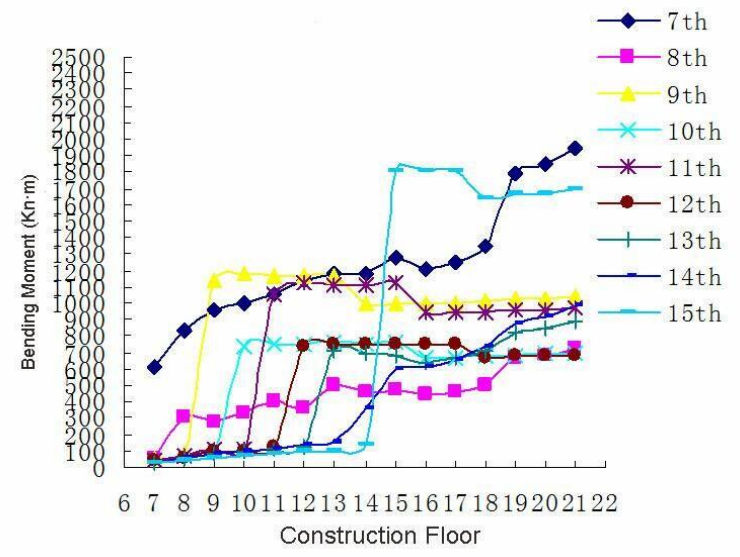

Figure 4.3.3. Steel beam internal force of E axle

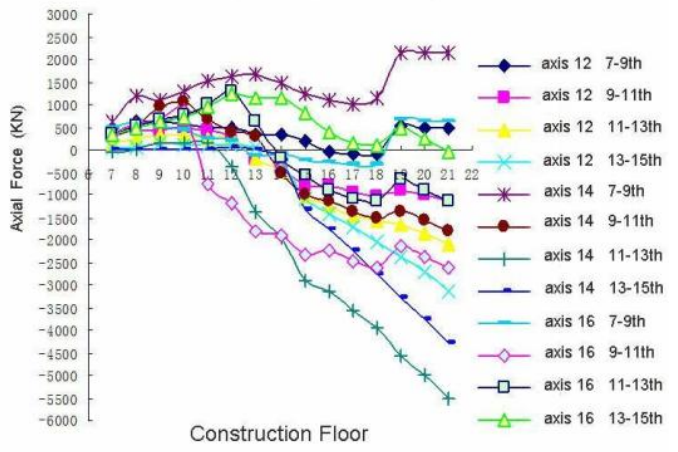

Figure 4.3.4. Left column internal force variation of $E$ axis

A case study of E shaft truss, it can be conclude results as fellow by analysis of internal force variation of the conversion layer truss in the construction process.

- Along with the progress of the construction, component is gradually forming, the structural load gradually increased and stiffness gradually formed, the beam internal force gradually increased, and the internal force of each bar is symmetrical;

- Structural internal force will be changed in structure span mutation, so construction monitoring should be strengthened in the construction process;

- During the construction stage, the influence of the secondary stress of steel truss is increased by $10 \%$ $5 \%$, and the secondary stress has great influence on the inclined column.

\section{CONCLUSION}

This paper introduces the construction process of the headquarters office building of the enterprise headquarters in the East New District, and puts forward the analysis method of the integral hoisting construction method, and analyzes the variation of the deflection and the internal force of the structure during the construction process and put forward the lattice column equivalent substitution principle. The influence of the secondary stress on the construction process is analyzed by the integral modeling and calculation. The strength, rigidity and stability of the structure are analyzed in this paper. The results show that the factor of construction process has little influence on the structure during the construction. Structure in the construction process satisfies with the requirements of structural safety.

In this paper, the research and analysis of the construction simulation of the construction of the office building of the enterprise headquarters in the New District of Liu Dong New District are discussed, and the following conclusions are drawn.

- In the construction process, the internal force of each member of the steel truss structure is gradually increased with the progress of the construction, and the deflection deformation increases gradually.

- Internal forces of rod do not exceed internal force of structure design for normal use stage; steel beam internal force in the structure change at the mutation, 
the construction monitoring should be strengthened in the construction process.

- In the construction stage, the steel truss is influenced by the secondary stress, the internal force of the structure is increased by $5 \% \sim 10 \%$, and the secondary stress has great influence on the inclined column.

- Structure in the construction stage satisfies with the safety the safety requirements.

\section{REFERENCES}

[1] Building Research Institute of China Metallurgical Group, Technical Specification of Steel-Reinforced Concrete Structures (YB 9082-2006) [S]. Beijing: Metallurgical industry press, 2007.1 3.

[2] Shantong, Zhong. Research and Application of steel-cocrete composite Structures in our Country [J]. Steel Structure, 2000, 04:4146.

[3] Berczynski Stefan, Wroblewski Tomasz. Experimental verification of natural vibration models of steel-concrete composite beams [J]. Journal of vibration and control' 2010, 16(14): 2057-2081.
[4] Shunichi Nakamura. Construction consideration for composite steeland-concrete floor systems [J]. Journal of Structural Engineering, 2002, 128(9): 1099-1110.

[5] Ningjun, Tang. Construction simulation Analysis on the Steel Reinforced Concrete Composite Structure [D]. Sichuan: College of Civil Engineering of Chongqing University, 2014.

[6] Zhendong, Ping. Research and engineering application of steel reinforced concrete structure at home and abroad at home and abroad [J]. Sichuan Architecture,2009,S1:195-197.

[7] Zhiyuan Cao.Construction Mechanics and time-varying Mechanics in Civil engineering $[\mathrm{J}]$. China Civil Engineering Journal, 2001, 34(3):41-46.

[8] YF Luo, R Yu, X Li, Static and linear buckling analysis of changed boundaiy beam, Steel and composite structures [C]. Proceedings of the 3rd international conference on steel and composite structures (ICSCS07), Manchester, UK, 30 July-1 August 2007, pp295-300.

[9] Ruili Li, Zhiyuan Cao.Construction mechanics analysis in tall buildings [J]. Chinese Journal of Computational Mechanics, 1999:157-161.

[10] ChoiCK, Kim E D. Multistory Frames under Sequential Gravity Loads. Journal of Structural Engineering, ASCE, 1985:2373-2384. 